\title{
Asymmetric Induction in the Amine-Induced Ring-Opening of 3-Bromo-5-ethyl-2-isopropylthiophene 1,1-Dioxide using L-Prolinol
}

\author{
Anders Tsirk,* Salo Gronowitz and Anna-Britta Hörnfeldt \\ Organic Chemistry 1, Chemical Center, Lund University, Box 124, 22100 Lund, Sweden
}

\section{Dedicated to Professor Lennart Eberson on the occasion of his 65 th birthday}

Tsirk, A., Gronowitz, S. and Hörnfeldt, A.-B., 1998. Asymmetric Induction in the Amine-Induced Ring-Opening of 3-Bromo-5-ethyl-2-isopropylthiophene 1,1Dioxide using L-Prolinol. - Acta Chem. Scand. 52: 533-540. (C) Acta Chemica Scandinavica 1998.

The diastereomers $\{1-(2 S)-[(2 R)(3 E, 5 Z)-5$-bromo-7-methyl-3,5-octadien-2-yl]tetrahydro-1H-pyrrol-2-yl $\}$ methanol (6) and $\{1-(2 S)-[(2 S)(3 E, 5 Z)-5$-bromo7-methyl-3,5-octadien-2-yl] tetrahydro-1 $H$-pyrrol-2-yl $\}$ methanol 7) were formed in a 65:35 ratio from 3-bromo-5-ethyl-2-isopropylthiophene, 1,1-dioxide (5) and L-prolinol. ( $5 R, 5 \mathrm{a} S, 8 R, 9 R, 9 \mathrm{a} S, 9 \mathrm{~b} S)$-Ethyl 7-bromo-8-isopropyl-5-methyl2,3,5,5a,8,9,9a,9b-octahydro-1 $H$-pyrrolo $[2,1-a]$ isoindole-9-carboxylate $(\mathbf{1 0})$ and $(5 S, 5 \mathrm{a} S, 8 R, 9 R, 9 \mathrm{a} S, 9 \mathrm{~b} S)$-ethyl 7-bromo-8-isopropyl-5-methyl-2,3,5,5a,8,9,9a,9boctahydro- $1 H$-pyrrolo[2,1-a] isoindole-9-carboxylate (12) were synthesized from 6 and 7 in order to establish the absolute configuration of the ring-opened products. The asymmetric induction at $\mathrm{C}(2)$ in the ring-opened products can be explained by the preferential formation of $E$ tautomers over $Z$ tautomers and the preferential formation of the $E(2 S)(15)$ and $Z(2 S)$ (17) enantiomers over the $E(2 R)(14)$ and $Z(2 R)(16)$ enantiomers when 5 tautomerizes. The tautomers form complexes with the L-prolinol dimers, and the enantiotopic face that will preferentially be attacked by another L-prolinol equivalent in a Michael addition will be the one anti to the dimer and syn to the isopropyl group.

In a previous paper we investigated which variables were important in the amine-induced ring-opening of thiophene 1,1-dioxides by use of multivariate optimization procedures. ${ }^{1}$ We found that the molar ratio between the amine and the dioxide and their respective concentrations were the most important. The polarity of the solvent was crucial: low dielectric constants, low dipole moments and low $E_{\mathrm{t}}$ values were preferred properties. The reaction temperature proved to be an independent variable, and could be kept constant within a range. Deuteriumlabelling experiments showed a small primary kinetic isotope effect when using 3-bromo-2-isopropyl-5trideuteriomethylthiophene 1,1-dioxide in the ring-opening reaction, suggesting that the rate-determining step was the initial proton abstraction of the tautomerization process. A 5.25:1 molar ratio of reagents was found to be optimal. This, together with a strong concentration dependence, suggest that a complex between several amine molecules and a dioxide molecule is formed prior to the tautomerization, and that this complex is maintained during the tautomerization process and possibly

* To whom correspondence should be addressed. until the Michael addition, i.e., the addition of the amine to the tautomerized exomethylene group. If this is true, what would happen if a chiral amine reacted with a 5ethyl- instead of a 5-methyl-substituted dioxide? Would there be an asymmetric induction at $\mathrm{C}(2)$ in the ringopened product? This question was the focus of the present investigation.

\section{Results}

The synthesis of the desired dioxide was a straightforward task: 2,3,5-tribromothiophene (1), was treated with secbutyllithium and acetone and then refluxed with oxalic acid under reduced pressure to give 3,5-dibromo-2isopropenylthiophene (2) in $74.5 \%$ yield. ${ }^{2}$ Hydrogenation with Wilkinson's catalyst yielded 3,5-dibromo-2isopropylthiophene (3) in $92 \%{ }^{2}$ Treatment of 3 with secbutyllithium and diethyl sulfate (CAUTION: Poison B; mutagenic, irritant) gave 3-bromo-5-ethyl-2-isopropylthiophene (4) in $80 \%$ yield. Oxidation of 4 with metachloroperbenzoic acid gave 3-bromo-5-ethyl-2-isopropylthiophene 1,1-dioxide (5) in 39\% yield (Scheme 1). 


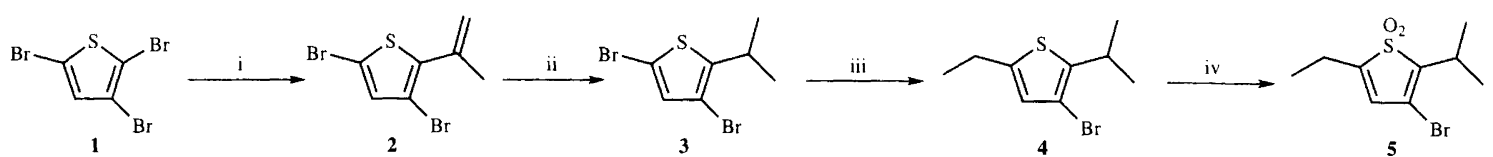

Scheme 1. i, (1) s-BuLi; (2) acetone; (3) $(\mathrm{COOH})_{2}$, yield 74.5\%: ii, $\mathrm{H}_{2}-$ Wilkinson's catalyst, yield $92 \%$, iii, (1) s-BuLi; (2) $\left(\mathrm{EtO}_{2} \mathrm{SO}_{2}\right.$, yield $80 \%$ : iv, mcpba, yield $39 \%$.

Compound 5 had the required properties for this investigation: an isopropyl group in the 2-position, making tautomerization from that side more difficult; and an ethyl group at $\mathrm{C}(5)$, which would give an intermediate with an enantiotopic face after the tautomerization. Using the optimized reaction conditions found for the reaction of amino alcohols with 3-bromo-2-isopropyl-5methylthiophene 1,1-dioxide - typically yielding more than $80 \%$ of the ring-opened product ${ }^{1}$ - led to a drastic drop in yield when 5 was reacted with L-prolinol. Decreasing the temperature to $80^{\circ} \mathrm{C}$ did not increase the yield to any great extent. A diastereomeric mixture of two ring-opened products was obtained in $29 \%$ total yield (Scheme 2$)$. The diastereomers $\{(2 S)-1$ $[(2 R)(3 E, 5 Z)$-5-bromo-7-methyl-3,5-octadien-2-yl] tetrahydro- $1 H$-pyrrol-2-yl $\}$ methanol (6) and $\{(2 S)-1$ [( $2 S)(3 E, 5 Z)$-5-bromo-7-methyl-3,5-octadien-2-yl] tetrahydro-1 $H$-pyrrol-2-yl $\}$ methanol (7) were formed in a $65: 35$ ratio, which was constant over the temperature range investigated: $80-116^{\circ} \mathrm{C}$. Clearly, asymmetric induction had taken place. After conferring with an expert, ${ }^{5}$ we were dissuaded from determining the absolute configuration at $\mathrm{C}(2)$ by circular dichroism. It would have been difficult to evaluate the CD spectra of 6 or 7 , since the chromophores were weak and the molecules were flexible. However, after transforming 6 and 7 into the trienes $(E)$-ethyl $3-\{(2 S)-1-(2 R$ and $2 S)(3 E, 5 Z)-5-$ bromo-7-methyl-3,5-octadien-2-yl] tetrahydro-1 $H$-pyrrol2-y1\}-2-propenoate ( 8 and 9 ) by using a Swern-HornerEmmons protocol, ${ }^{6,7}$ we were able to cyclize the products in a thermal intramolecular Diels-Alder reaction (IMDA). The Swern-Horner-Emmons reaction gave a $64 \%$ overall yield of 8 and 9 , and the IMDA gave a mixture of four components in $96 \%$ yield: 8 gave a mixture of 10 and 11 in a ratio of $86: 14$, while 9 gave a mixture of 12 and 13 in a ratio of $90: 10$. The relative configuration of these IMDA products could be determined through standard NMR techniques. Once determined, these configurations provided the necessary information for deducing the absolute configuration of 6-9.

The IMDA isomers were separated by high performance liquid chromatography, and were distinguished and characterized through analysis of their respective COSY, HETCOR, HETCOR long-range and NOESY spectra.

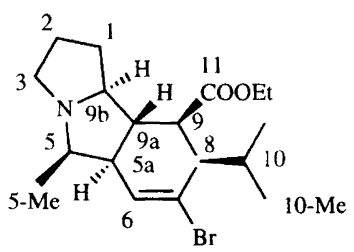

Fig. 1. trans-Fused IMDA product 10.

Compound 10 (Fig. 1) was the major product from the cyclization of the major triene 8 . The NOESY correlation pattern for $\mathbf{1 0}$ was as follows: 5 -Me correlated to $5-\mathrm{H}, 6-\mathrm{H}, 9 \mathrm{a}-\mathrm{H}$ and $3-\mathrm{H}_{\mathrm{eq}} ; 5 \mathrm{a}-\mathrm{H}, 8-\mathrm{H}$ and $9-\mathrm{H}$ all correlated to each other; $9 \mathrm{~b}-\mathrm{H}$ correlated to $9-\mathrm{H}$ and $1-\mathrm{H}_{\text {eq }}$. The coupling constant for $5-\mathrm{H}$, showing a quintet, was $7.2 \mathrm{~Hz}$; the coupling constants for $5 \mathrm{a}-\mathrm{H}$ were 11.4 and $7.2 \mathrm{~Hz}$; the coupling constant for $9 \mathrm{a}-\mathrm{H}$, giving a quartet, was $11.4 \mathrm{~Hz}$; a $11.4 \mathrm{~Hz}$ coupling constant was found for both $9 \mathrm{~b}-\mathrm{H}$ and $9-\mathrm{H}$; for $9-\mathrm{H}$, a double doublet, a $6.6 \mathrm{~Hz}$ coupling to $8-\mathrm{H}$ was also observed. These couplings and NOESY patterns suggest that $5-\mathrm{H}$ and
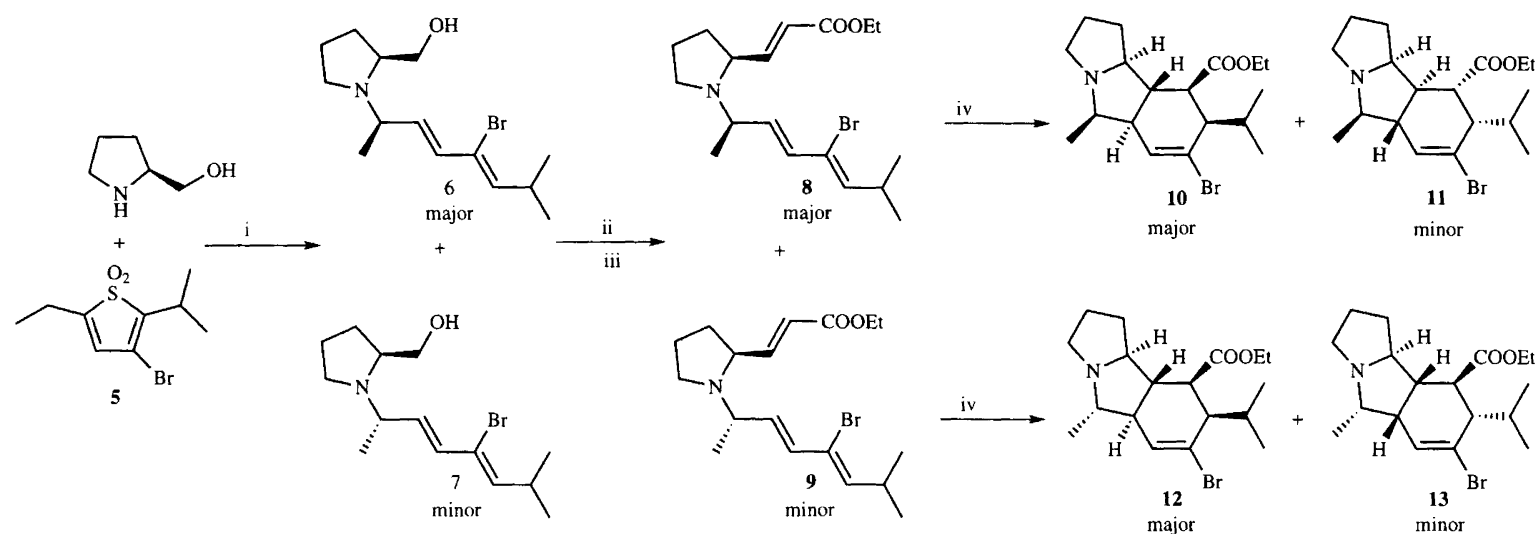

Scheme 2. i, ring-opening: p-xylene, argon, $90^{\circ} \mathrm{C}, 2.5 \mathrm{~h}, 29 \%$; ii, Swern oxidation: (1) $\mathrm{CH}_{2} \mathrm{Cl}_{2},-78{ }^{\circ} \mathrm{C}$, argon, $(\mathrm{COCL})_{2}, \mathrm{DMSO}$; (2) $\mathrm{Et}_{3} \mathrm{~N}, 2 \mathrm{~h}$; iii. Horner-Emmons reaction: $\mathrm{THF}, \mathrm{NaH},(\mathrm{EtO})_{2} \mathrm{POCH}_{2} \mathrm{COOEt}$, r.t., $1.5 \mathrm{~h}, 64 \%$ overall; iv. thermal Diels-Alder reaction: toluene, argon, $100-120^{\circ} \mathrm{C}, 1-2$ days, $96 \%$. 
5a-H are cis to each other; that $9 \mathrm{a}-\mathrm{H}$ is trans to $5 \mathrm{a}-\mathrm{H}$, $9-\mathrm{H}$ and $9 \mathrm{~b}-\mathrm{H}$; and that $8-\mathrm{H}$ and $9-\mathrm{H}$ are cis to each other. Therefore, $\mathbf{1 0}$ is the trans fused isomer with a $5 R$ configuration: $(5 R, 5 \mathrm{a} S, 8 R, 9 R, 9 \mathrm{a} S, 9 \mathrm{~b} S)$-ethyl 7-bromo-8isopropyl - 5 - methyl - 2,3,5,5a,8,9,9a,9b - octahydro - $1 \mathrm{H}$ pyrrolo[2,1- $a$ ] isoindole-9-carboxylate, formed via addition of the dienophile form above the diene plane. Compound 12 was the major product from the cyclization of the minor triene 9. The NOESY correlation pattern for 12 was as follows: $5-\mathrm{Me}$ correlated to $5-\mathrm{H}$, $5 \mathrm{a}-\mathrm{H}$ and 6-H; 5a-H, 8- $\mathrm{H}$ and 9-H correlated all to each other; $9 \mathrm{~b}-\mathrm{H}$ correlated to $1-\mathrm{H}, 5 \mathrm{a}-\mathrm{H}$ and $9-\mathrm{H}$. The coupling constants for $5-\mathrm{H}$ were $6.0 \mathrm{~Hz}$ and $11.3 \mathrm{~Hz}$; the coupling constant for $5 \mathrm{a}-\mathrm{H}$, showing a triplet, was $11.3 \mathrm{~Hz}$; the coupling constant for $9 \mathrm{a}-\mathrm{H}$, giving a quartet, was $11.3 \mathrm{~Hz}$; a $11.3 \mathrm{~Hz}$ coupling constant was also found for $9 \mathrm{~b}-\mathrm{H}$ and $9-\mathrm{H}$. These coupling and NOESY patterns suggest that $5-\mathrm{H}$ and $5 \mathrm{a}-\mathrm{H}$ are trans to each other; and that $9 \mathrm{a}-\mathrm{H}$ is trans to $5 \mathrm{a}-\mathrm{H}, 9-\mathrm{H}$ and $9 \mathrm{~b}-\mathrm{H}$. Therefore, 12 is the trans fused isomer with a $5 S$ configuration: ( $5 S, 5 \mathrm{a} S, 8 R, 9 R, 9 \mathrm{a} S, 9 \mathrm{~b} S)$-ethyl 7-bromo - 8 - isopropyl - 5methyl - 2,3,5,5a,8,9,9a,9b - octahydro - $1 H$ - pyrrolo[2,1 a] isoindole-9-carboxylate, formed via addition of the dienophile from above the diene plane. If we look at the dihedral angles between $\mathrm{C}(5-\mathrm{Me})$ and $\mathrm{C}(3), \mathrm{C}(6)$ and $\mathrm{C}(9 \mathrm{a})$, respectively, we should expect an upfield shift for $\mathrm{C}(5-\mathrm{Me}), \mathrm{C}(3)$ and $\mathrm{C}(6)$ and a downfield shift for $\mathrm{C}(9 \mathrm{a})$ of several ppm in the ${ }^{13} \mathrm{C}$ NMR spectrum of compound $\mathbf{1 0}$ relative to compound $\mathbf{1 2}$. Indeed, this was seen, which further supports the configurational assignments of these isomers. Compound $\mathbf{1 3}$ was the minor product from the cyclization of the minor triene 9 . In the ${ }^{1} \mathrm{H}$ NMR spectra of 13 and 12 the signal of 10-CH was shifted downfield for the former. Also, the carbons C(10) and C(11) were shifted downfield in the ${ }^{13} \mathrm{C}$ NMR spectrum of 13 , which can be attributed to a $\gamma$-substituent effect. ${ }^{8}$ We have seen in previous work that these trends are significant for $\mathrm{cis}$ fused compounds. ${ }^{4}$ In the NOESY of $13,5 \mathrm{a}-\mathrm{H}$ correlated to 5-H, 5-Me, 6-H and 9a-H. In addition, 5-Me correlated to both the $3-\mathrm{H}$ protons and to $6-\mathrm{H}$. The coupling constants for $5-\mathrm{H}$ were 6.6 and $5.9 \mathrm{~Hz}$; the coupling constants for $5 \mathrm{a}-\mathrm{H}$ were 5.9 and $7.3 \mathrm{~Hz}$; the coupling constants for $9 \mathrm{a}-\mathrm{H}$ were 12.1 and $7.3 \mathrm{~Hz}$; in the absorption of 9-H two coupling constants were also found: 12.1 and $9.5 \mathrm{~Hz}$; for $8-\mathrm{H}$ a $9.5 \mathrm{~Hz}$ coupling constant was observed. This data establishes a cis relationship between 5- $\mathrm{H}$ and $5 \mathrm{a}-\mathrm{H}$ and between $5 \mathrm{a}-\mathrm{H}$ and $9 \mathrm{a}-\mathrm{H}$; and a trans relationship between $9 \mathrm{a}-\mathrm{H}$ and $9-\mathrm{H}$ and between $9-\mathrm{H}$ and $8-\mathrm{H}$. These patterns imply that $\mathbf{1 3}$ is the cis fused isomer with a $5 S$ configuration: $(5 S, 5 \mathrm{a} R, 8 S, 9 R, 9 \mathrm{a} S, 9 \mathrm{~b} S)$-ethyl 7bromo - 8 - isopropyl - 5 - methyl - 2,3,5,5a,8,9,9a,9b - octahydro- $1 H$-pyrrolo[2,1-a] isoindole-9-carboxylate, formed via addition of the dienophile from below the diene plane. Compound $\mathbf{1 1}$ was the minor product from the cyclization of the major triene $\mathbf{8}$. Neither the proton nor the carbon shifts in the six-membered ring or in the isopropyl or the ethoxycarbonyl group of $\mathbf{1 1}$ differed significantly from the corresponding ones in 10; there was no cis/trans relationship between the two compounds. In the NOESY spectrum of the former, 5-Me correlated to $3-\mathrm{H}, 5-\mathrm{H}$ and $5 \mathrm{a}-\mathrm{H}$; and $9 \mathrm{a}-\mathrm{H}$ correlated to $5-\mathrm{H}$, the $10-\mathrm{Me}$ groups and $9 \mathrm{~b}-\mathrm{H}$. A $12.0 \mathrm{~Hz}$ coupling constant was found for $5-\mathrm{H}, 5 \mathrm{a}-\mathrm{H}, 9 \mathrm{a}-\mathrm{H}$ and $9-\mathrm{H}$; an $8.0 \mathrm{~Hz}$ coupling constant was found for $9 \mathrm{~b}-\mathrm{H}$ and $9 \mathrm{a}-\mathrm{H}$; a $5.6 \mathrm{~Hz}$ coupling constant was found for $9-\mathrm{H}$ and $8-\mathrm{H}$. These data establish a trans relationship between $5-\mathrm{H}$ and $5 \mathrm{a}-\mathrm{H}$, between $5 \mathrm{a}-\mathrm{H}$ and $9 \mathrm{a}-\mathrm{H}$ and between $9 \mathrm{a}-\mathrm{H}$ and $9-\mathrm{H}$; and a cis relationship between $9 \mathrm{a}-\mathrm{H}$ and $9 \mathrm{~b}-\mathrm{H}$ and between $9-\mathrm{H}$ and $8-\mathrm{H}$. The conclusion is that 11 is the trans fused isomer with a $5 R$ configuration formed via addition of the dienophile from below the diene plane: $(5 R, 5 \mathrm{a} R, 8 S, 9 S, 9 \mathrm{a} R, 9 \mathrm{~b} S)$-ethyl 7-bromo-8isopropyl-5-methyl-2,3,5,5a,8,9,9a,9b-octahydro- $1 H$ pyrrolo $[2,1-a]$ isoindole-9-carboxylate.

\section{Discussion}

How do we explain the asymmetric induction in view of the proposed mechanism for the ring-opening reaction? ${ }^{1,9}$ This is not easy, since we have to consider non-detectable intermediates and other transient structures. Although highly speculative, the discussion is warranted and might serve as a starting point for further investigation. In short, the ring-opening reaction is initiated by a proton abstraction at $\mathrm{CH}_{2}$ (C5) in 5; the proton is then transferred intramolecularly to $\mathrm{C}(2)$, which becomes protonated to give an ethylidene tautomer. ${ }^{1}$ In this case, there are four possible ethylidene tautomers: $E(2 R) \mathbf{1 4}$, $E(2 S) 15, Z(2 R) 16$ and $Z(2 S) 17$ (Fig. 2). After addition of the amine to these vinyl sulfone analogues, an intermediate cis sulfolene is formed. The actual ringopening is a disrotatory chelotropic elimination of $\mathrm{SO}_{2}{ }^{*}$ from $c i s$ sulfolene, because only $E, E$ dienes ${ }^{10,11}$ with respect to the carbon chain are formed (Scheme 3). ${ }^{1,4,9,12-14}$ In a Michael addition to vinyl sulfones the reaction is second order in amine when benzene is the solvent, while it is first order in ethanol. ${ }^{15}$ The authors argue that an extra amine molecule is needed in the transition state (TS); in ethanol a solvent molecule takes this role. They also confirm that the reaction

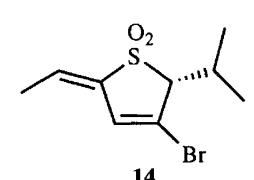

14

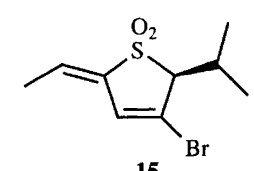

15

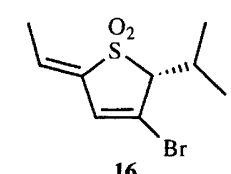

16

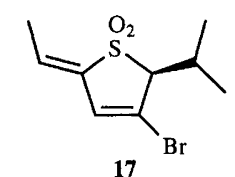

17
Fig. 2. The tautomers $E(2 R) 14, E(2 S) 15, Z(2 R) 16$ and $Z(2 S) 17$.

* The formation of $\mathrm{SO}_{2}$ has been established by trapping the evolved gas in $\mathrm{KMnO}_{4}$ solution and observing the formation of $\mathrm{MnO}_{2}$. 


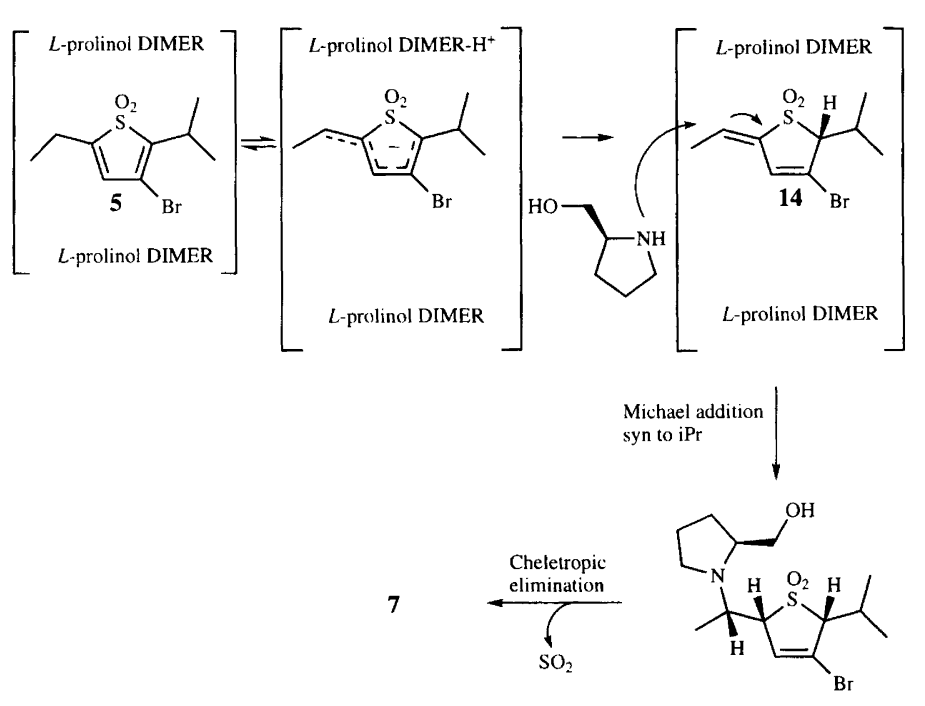

Scheme 3. The tautomerization and ring-opening of $\mathbf{5}$.

proceeds via an anionic TS. $^{16}$ Very negative activation entropies speak for a highly ordered transition state, sensitive to the steric demands of the reagents. ${ }^{17}$ This implies that a free amine is favoured in the attack. Furthermore, a nucleophilic attack on a double bond proceeds with a tetrahedral attack angle of $109.5^{\circ}(\mathrm{NC}=\mathrm{C}$ angle) and reaches the TS at a distance $(\mathrm{N}-\mathrm{C})$ of about $2 \AA,{ }^{18-20}$ which means that $L$-prolinol approaches the tautomer from the outside and that the configuration at $\mathrm{C}(2)$ in the dioxide will have a small direct influence on the diastereoselectivity, since the energetics of steric interactions are proportional to $r^{-6}$. In a non-polar solvent such as $p$-xylene L-prolinol may form doubly hydrogen-bonded dimers, and in doing so it will gain some extra stabilization energy. Figure 3 shows such a dimer (18) with PM3-optimized geometry. ${ }^{21}$ This dimer can form a weak complex with 5 , gaining $2.2 \mathrm{kcal} \mathrm{mol}^{-1}$ compared with the free dimer and the free dioxide. Adding another dimer on the other side of $\mathbf{5}$ also leads to some extra stabilization. A $2: 1$ complex is thus conceivable, where the hydrogen bonded dimers lie separated with the dioxide in between. An optimum molar ratio of reagents of 5.25:1 was found. ${ }^{1}$ When proton abstraction occurs, the protonated dimer will necessarily come closer to the carbanion; the closer they get the more the configurational differences will manifest themselves. We therefore suspect that the asymmetric induc-

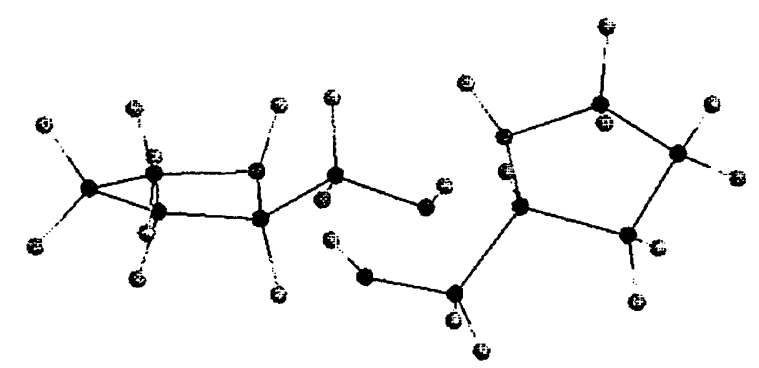

Fig. 3. The L-prolinol dimer (18). tion takes place when $\mathrm{C}(2)$ of the carbanion is protonated. Immediately after this protonation a complex such as $19 \dagger$ exists. This complex between 18 and 14 (Fig. 4) is considerably closer than the one between 18 and 5: the extra stabilization energy of $5.2 \mathrm{kcal} \mathrm{mol}^{-1}$ is mainly caused by an increase in electrostatic interactions, but probably also to some extent by increased charge transfer interactions. ${ }^{22}$ An important observation made earlier was the high degree of deuterium incorporation at $\mathrm{C}(2)$ in the diene when 3-bromo-2-isopropyl-5-trideuteriomethyl-thiophene 1,1-dioxide was ring-opened; this indicates that the Michael addition takes place shortly after the tautomer formation and before any

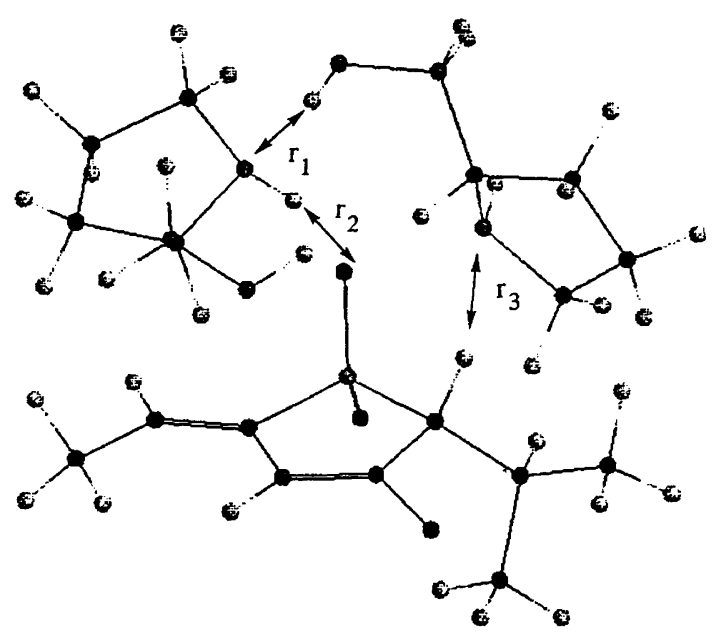

Fig. 4. Complex (19) between the L-prolinol dimer (18) and the $E(2 S)$ tautomer (14). $r_{1}=\mathrm{N}-\mathrm{H}(\mathrm{O}) 1.84 \AA ; r_{2}=(\mathrm{N}) \mathrm{H}-\mathrm{O}(\mathrm{S})$ $2.70 \AA ; r_{3}=N-H(C 2) 2.78 \AA$.

$\dagger$ Complex 19 is the lowest of many low-energy conformations found when combining 18 and $\mathbf{1 4}$ in different ways; it is most likely not the lowest-lying conformation, but can serve as a model for discussion. Combining 18 syn to the isopropyl group of $\mathbf{1 4}$ led to the weakest complexes. 
significant complex dissociation has occurred. ${ }^{1}$ If 19 is more or less intact, another L-prolinol molecule can attack the tautomer from the opposite side, i.e., syn to the isopropyl group. The dimer will not only stabilize the build-up of negative charge in the transition state of the $\mathrm{S}_{\mathrm{N}} 2^{\prime}$ reaction, it can also provide protons for the protonation of the intermediate $\alpha$-sulfonyl carbanion, yielding a cis sulfolene. Cram's rule would favour an attack anti to the bulky complexing dimer, i.e., syn to the isopropyl group; and, in the context of a Michael addition with a highly ordered transition state vide supra, ${ }^{17}$ an attack syn to the complexing L-prolinol moiety would be disfavoured. Consequently, we believe that the favoured attack is anti to the complexing dimer and syn to the isopropyl group, and that the asymmetric induction depends mainly on an unequal formation of tautomers.

The small primary kinetic isotope effect could be explained by assuming an early reactant-like transition state for the initial proton abstraction. ${ }^{1}$ The energy difference between the pre- $E$ and the pre- $Z$ conformations is only about $0.3 \mathrm{kcal} \mathrm{mol}^{-1}$ in favour of the former; the $E$ tautomer is also thermodynamically favoured by $1.1 \mathrm{kcal} \mathrm{mol}^{-1}$ over the $Z$ tautomer. It is therefore likely that the $E$ tautomers form preferentially, but in unequal amounts. Subsequently, the major diastereomer $\mathbf{6}$ is formed when $\mathbf{1 5}$ is attacked syn to the isopropyl group and anti to the complexing dimer, while the minor diastereomer 7 is formed when 14 is attacked $s y n$ to the isopropyl group and anti to the complexing dimer. The same line of argument can be applied to the reactions of the $Z$ tautomers 16 and 17, in which case the total reaction becomes more racemic.

\section{Conclusions}

The asymmetric induction at $\mathrm{C}(2)$ in the ring-opened products can be explained by the preferential formation of $E$ tautomers over $Z$ tautomers and the preferential formation of the $E(2 S)(15)$ and $Z(2 S)$ (17) enantiomers over the $E(2 R)(14)$ and $Z(2 R)(16)$ enantiomers. The tautomers form complexes with the L-prolinol dimers, and the enantiotopic face that will be preferentially attacked by another L-prolinol equivalent will be the one anti to the dimer and syn to the isopropyl group. The dimer stabilizes the negative charge in the TS of the Michael addition and protonates the $\alpha$-sulfonyl carbanion to give a cis sulfolene. The cis sulfolene ringopens to give an $E, E$ diene with respect to the carbon chain exclusively.

\section{Experimental}

General. Semiempirical calculations were carried out using SPARTAN ${ }^{21}$ on a Silicon Graphics Indy machine. Geometry optimizations for 5, 14, 16, 18 and 19 were performed using the RHF/PM3 force field using default parametrization. The ${ }^{1} \mathrm{H}$ NMR (at $400.13 \mathrm{MHz}$ ), ${ }^{13} \mathrm{C}$
NMR (at 100.61 MHz), gradient COSY, HETCOR, HETCOR long-range and NOESY spectra were recorded on a Bruker ARX400 instrument; $\delta$ is in ppm relative to residual solvent signals; $J$ is in $\mathrm{Hz}$; Deuteriochloroform was consistently used as the solvent. The mass spectra were recorded on a JEOL-SX 102 mass spectrometer at $70 \mathrm{eV} ; m / z$ (rel. \%). GLC analyses were carried out on a Varian 3600 gas chromatograph equipped with an SPB5 capillary column. The IR spectra were recorded on a Perkin-Elmer 298 infrared spectrophotometer; $v$ is in $\mathrm{cm}^{-1}$. Optical rotations were measured at room temperature on a Perkin-Elmer 241 polarimeter. Separations on a Chromatotron ${ }^{\mathrm{TM}}$ were made using rotors coated with Merck silica gel $60\left(60 \mathrm{PF}_{254}\right)$ containing gypsum. HPLC chromatography was performed on a semipreparative Nucleosil silica column $(500 \times 10 \mathrm{~mm})$. All solvents were distilled and purified according to standard procedures prior to use. Dichloromethane was distilled from phosphorus pentoxide. The reagents dimethyl sulfoxide and triethylamine were freshly distilled from calcium hydride. Oxalyl chloride was distilled from $4 \AA$ molecular sieves. Other commercial starting materials were used without further purification.

3,5-Dibromo-2-isopropenylthiophene (2). ${ }^{2}$ sec-Butyllithium $(26.9 \mathrm{ml}, 1.3 \mathrm{M}, 35 \mathrm{mmol})$ was added dropwise over $1 \mathrm{~h}$ to a solution of 2,3,5-tribromothiophene (1) $(10.69 \mathrm{~g}, 33.0 \mathrm{mmol})$ in anhydrous ether $(20 \mathrm{ml})$ under an argon atmosphere at $-78^{\circ} \mathrm{C}$. After $30 \mathrm{~min}$ acetone $(2.69 \mathrm{ml}, 36.67 \mathrm{mmol})$ in anhydrous ether $(7 \mathrm{ml})$ was added slowly; the reaction mixture was stirred for $40 \mathrm{~min}$ at $-78^{\circ} \mathrm{C}$, and was then allowed to reach ambient temperature over $1 \mathrm{~h}$. The reaction mixture was poured onto an ice- $\mathrm{HCl}$ slurry after which the water phase was extracted three times with ether and the combined ethereal layers were washed with water, dried over magnesium sulfate and evaporated in vacuo. The crude product was refluxed for $1 \mathrm{~h}$ with oxalic acid $(0.33 \mathrm{~g})$ at $61-63^{\circ} \mathrm{C} / 1.50 \mathrm{~Pa}$. Distillation under argon gave $6.95 \mathrm{~g}$ $(74.5 \%)$ of the title compound; b.p. $104{ }^{\circ} \mathrm{C} / 0.13 \mathrm{~Pa} .{ }^{1} \mathrm{H}$ NMR: $\delta 6.92(1 \mathrm{H}, \mathrm{H}-4), 5.48(1 \mathrm{H}, \mathrm{C}=\mathrm{CH}), 5.25(1 \mathrm{H}$, $\mathrm{C}=\mathrm{CH}) 2.15\left(3 \mathrm{H}, \mathrm{CH}_{3}\right) \cdot{ }^{13} \mathrm{C}$ NMR: $\delta$ 135.77, 133.69, $118.00,110.54,106.05,23.62$.

3,5-Dibromo-2-isopropylthiophene (3). ${ }^{2}$ 3,5-Dibromo-2isopropenylthiophene (2) $(6.80 \mathrm{~g}, 24.1 \mathrm{mmol})$ was dissolved in a $4: 1$ mixture of toluene and heptane $(63 \mathrm{ml})$ and $\left(\mathrm{PPh}_{3}\right)_{3} \mathrm{RhCl}(200 \mathrm{mg})$ was added; the flask was placed in a Parr hydrogenation apparatus and flushed three times with hydrogen. Complete hydrogenation was

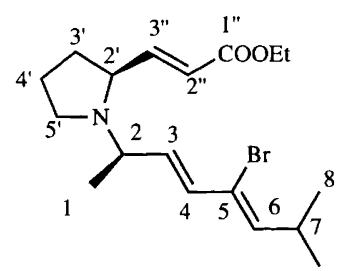

Fig. 5. Numbering for NMR assignments, see also Fig. 1. 
achieved after $20 \mathrm{~h}$ at a working pressure of $3.2 \mathrm{~kg} \mathrm{~cm}^{-2}$. After filtration through Celite the product was distilled under argon to give $6.30 \mathrm{~g} \mathrm{(92 \% )}$ of the title compound, b.p. $66-68^{\circ} \mathrm{C} / 0.01 \mathrm{~Pa} .{ }^{1} \mathrm{H}$ NMR: $\delta 6.94(1 \mathrm{H}, \mathrm{H}-4), 3.33$ [septet, $\left.1 \mathrm{H}, \quad \mathrm{CH}\left(\mathrm{CH}_{3}\right)_{2}, \quad J=6.9\right], \quad 1.31 \quad[\mathrm{~d}, \quad 6 \mathrm{H}$, $\left.\mathrm{CH}\left(\mathrm{CH}_{3}\right)_{2}, J=6.9\right] .{ }^{13} \mathrm{C}$ NMR: $\delta 149.30,136.20,109.22$, $106.35,30.67,24.07$.

3-Bromo-5-ethyl-2-isopropylthiophene (4). 3,5-Dibromo2-isopropylthiophene (3) $(4.9 \mathrm{~g}, 17.27 \mathrm{mmol})$ was dissolved in anhydrous ether $(40 \mathrm{ml})$ and cooled to $-78^{\circ} \mathrm{C}$ under an argon atmosphere. $1.3 \mathrm{M}$ sec-Butyllithium $(13.70 \mathrm{ml}, 17.83 \mathrm{mmol})$ was then added dropwise over $30 \mathrm{~min}$. After $1 \mathrm{~h}$ diethyl sulfate (CAUTION) $(2.80 \mathrm{ml}$, $21.39 \mathrm{mmol})$ in anhydrous ether $(20 \mathrm{ml})$ was added via a syringe, and the reaction mixture was allowed to reach ambient temperature over $75 \mathrm{~min}$. The reaction mixture was quenched with water and finally a large volume of $10 \%$ ammonia in ethanol was poured into the reaction vessel; this mixture was left overnight. The mixture was extracted several times with ether; the ethereal layers were washed with saturated ammonium chloride solution and water, dried over magnesium sulfate and evaporated in vacuo to give a $4: 1$ mixture of 5-alkylated:5-protonated thiophenes in quantitative yield. These were separated on a Chromatotron ${ }^{\mathrm{TM}}$ using heptane as the eluent to give $3.22 \mathrm{~g}(80 \%)$ of the title compound as an oil. ${ }^{1} \mathrm{H}$ NMR: $\delta 6.26(\mathrm{t}, 1 \mathrm{H}, \mathrm{H}-4, J=2.1), 3.10$ [septet, $\left.1 \mathrm{H}, \mathrm{CH}\left(\mathrm{CH}_{3}\right)_{2}, J=7.1\right), 2.50\left(\mathrm{dq}, 2 \mathrm{H}, \mathrm{CH}_{2}, J=2.1\right.$, $.7 .0), 1.39\left[\mathrm{~d}, 6 \mathrm{H}, \mathrm{CH}\left(\mathrm{CH}_{3}\right)_{2}, J=7.1\right], 1.24(\mathrm{t}, 3 \mathrm{H}$, $\left.\mathrm{CH}_{2} \mathrm{CH}_{3}, J=7.0\right) .{ }^{13} \mathrm{C}$ NMR: $\delta 146.37(\mathrm{C}-2), 143.39$ $(\mathrm{C}-5), 125.12(\mathrm{C}-4), 119.37(\mathrm{C}-3), 28.88\left[\mathrm{CH}\left(\mathrm{CH}_{3}\right)_{2}\right]$, $19.66\left[\mathrm{CH}\left(\mathrm{CH}_{3}\right)_{2}\right], 17.09\left(\mathrm{CH}_{2} \mathrm{CH}_{3}\right), 10.73\left(\mathrm{CH}_{2} \mathrm{CH}_{3}\right)$. HRMS: 231.9914 , calc. for $\mathrm{C}_{9} \mathrm{H}_{13} \mathrm{BrS}$ : 231.9921. MS: $m / z(\%) 232 / 234\left(25, M^{+}\right), 217 / 219$ (100), 138 (16), $123(15)$.

3-Bromo-5-ethyl-2-isopropylthiophene 1,1-dioxide (5) was synthesized according to the literature. ${ }^{3,4}$ The product was obtained when $4(2.31 \mathrm{~g}, 9.91 \mathrm{mmol})$ was oxidized and chromatographed on a Chromatotron ${ }^{\mathrm{TM}}$ using gradient elution starting from heptane and ending with diethyl ether. The title compound $1.42 \mathrm{~g} \mathrm{(39 \% )}$ was obtained as a clear oil. ${ }^{1} \mathrm{H}$ NMR: $\delta 6.26(\mathrm{t}, 1 \mathrm{H}, \mathrm{H}-4, J=2.1), 3.10$ [septet, $\left.1 \mathrm{H}, \mathrm{CH}\left(\mathrm{CH}_{3}\right)_{2}, \quad J=7.1\right], 2.50(\mathrm{dq}, 2 \mathrm{H}$, $\left.\mathrm{CH}_{2} \mathrm{CH}_{3}, J=7.0,2.1 \mathrm{~Hz}\right), 1.39\left[\mathrm{~d}, 6 \mathrm{H}, \mathrm{CH}\left(\mathrm{CH}_{3}\right)_{2}, J=\right.$ 7.1], 1.24 (t, $\left.3 \mathrm{H}, \mathrm{CH}_{2} \mathrm{CH}_{3}, J=7.0\right) .{ }^{13} \mathrm{C} \mathrm{NMR:} \delta 146.37$ (C-2), 143.39 (C-5), 125.12 (C-4), 119.37 (C-3), 28.88 $\left[\mathrm{CH}\left(\mathrm{CH}_{3}\right)_{2}\right], 19.66\left[\mathrm{CH}\left(\mathrm{CH}_{3}\right)_{2}\right], 17.09\left(\mathrm{CH}_{2} \mathrm{CH}_{3}\right), 10.73$ $\left(\mathrm{CH}_{2} \mathrm{CH}_{3}\right)$. HRMS: 263.9819 , calc. for $\mathrm{C}_{9} \mathrm{H}_{13} \mathrm{BrO}_{2} \mathrm{~S}$ : 263.9820. MS: $m / z(\%)$ 264/266 (35, $\left.M^{+}\right), 201(35), 185$ (63), $121(100)$.

Synthesis of 6 and 7 via ring-opening of $5{ }^{1}$ L-Prolinol (1599.59 mg, $15.82 \mathrm{mmol}$ ) and 5 (798.16 mg, $3.01 \mathrm{mmol}$ ) were dissolved in $p$-xylene $(24.0 \mathrm{ml})$ and placed with a condenser in an oil bath at $80^{\circ} \mathrm{C}$ under argon. The reaction was complete after $5.25 \mathrm{~h}$, as determined by TLC and GLC; the reaction mixture was diluted with diethyl ether and washed with water to remove the excess of L-prolinol. The ethereal phase was dried over magnesium sulfate and then evaporated in vacuo to give a crude product. The components were separated on a Chromatotron $^{\mathrm{TM}}$ with heptane-ethyl acetate-triethylamine-methanol $(90: 10: 5: 1)$ as the eluent.

$\{(2 \mathrm{~S})-1-[(2 \mathrm{R})(3 \mathrm{E}, 5 \mathrm{Z})-5$-Bromo-7-methyl-3,5-octadien2-yl] tetrahydro-1H-pyrrol-2-yl methanol (6). Yield: $171.50 \mathrm{mg}(19 \%)$ IR (film): v 3406b (OH), 1634m (C=C stretch, conjug. diene), $1598 \mathrm{~m}, 1456 \mathrm{~s}, 1378 \mathrm{~s}, 1300 \mathrm{~s}$, $1168 \mathrm{~s}, 1118 \mathrm{~s}, 1031 \mathrm{~s}, 953 \mathrm{~s}$ (CH bend, trans-RCH-CHR). ${ }^{1} \mathrm{H}$ NMR: $\delta 6.04(\mathrm{~d}, 1 \mathrm{H}, 5-\mathrm{H}, J=14.9), 6.00(\mathrm{dd}, 1 \mathrm{H}$, 3-H $J=14.9,6.1$ ), 5.69 (d, $1 \mathrm{H}, 6-\mathrm{H} J=8.8$ ), 3.46 (dd, $\left.1 \mathrm{H}, 1^{\prime \prime}-\mathrm{CH}_{2} J=-10.6,4.6\right), 3.34(\mathrm{~m}, 1 \mathrm{H}, 2-\mathrm{H}, J=6.6$, $6.1 \mathrm{~Hz}$ ), $3.30\left(\mathrm{dd}, 1 \mathrm{H}, 1^{\prime \prime}-\mathrm{CH}_{2} J=-10.6,3.0\right), 2.94(\mathrm{~m}$, $\left.2 \mathrm{H}, 2^{\prime}-\mathrm{H}, 5^{\prime}-\mathrm{H}_{\text {eq }}\right), 2.81(\mathrm{~m}, 1 \mathrm{H}, 7-\mathrm{H}, J=8.8,6.7), 2.50$ $\left(1 \mathrm{H}, 5^{\prime}-\mathrm{H}_{\mathrm{ax}}\right), 1.87-1.60\left(\mathrm{~m}, 4 \mathrm{H}, 3^{\prime}-, 4^{\prime}-\mathrm{H}_{2}\right), 1.15(\mathrm{~d}$, $\left.3 \mathrm{H}, 1-\mathrm{CH}_{3} J=6.8\right), 1.00\left(\mathrm{~d}, 6 \mathrm{H}, 8-\mathrm{CH}_{3}, J=6.7\right) .{ }^{13} \mathrm{C}$ NMR: $\delta 140.51$ (C-6), 136.88 (C-3), 129.31 (C-4), 122.43 (C-5), 63.94 (C-11"), 60.69 (C-2'), 58.11 (C-2), 50.34 $\left(\mathrm{C}-5^{\prime}\right), 31.10$ (C-7), 29.20 (C-3'), 24.52 (C-4'), 21.75 (C-8), 17.37 (C-1). HRMS: 302.1104, calc. for $\mathrm{C} 14 \mathrm{H}_{2}$ 5BrNO$(\mathrm{M}+\mathrm{H}): 302.1119$. MS: $m_{i}=(\%) 302,304$ [92, $(M+\mathrm{H})+], 270 / 272(45), 222(95), 123$ (100).

$\{(2 \mathrm{~S})-1-[(2 \mathrm{~S})(3 \mathrm{E}, 5 \mathrm{Z})$-5-Bromo-7-methyl-3,5-octadien2-yl] tetrahydro-1H-pyrrol-2-yl\}methanol (7). Yield: $92.34 \mathrm{mg}$ (10\%). IR (film): v 3406b (OH), 1634m (C=C stretch, conjug. diene), $1598 \mathrm{~m}, 1456 \mathrm{~s}, 1378 \mathrm{~s}, 1300 \mathrm{~s}$, $1168 \mathrm{~s}, 1118 \mathrm{~s}, 1031 \mathrm{~s}, 953 \mathrm{~s}(\mathrm{CH}$ bend, trans $-\mathrm{RCH}=\mathrm{CHR})$. ${ }^{1} \mathrm{H}$ NMR: $\delta 6.04(\mathrm{~d}, 1 \mathrm{H}, 4-\mathrm{H}, J=14.9 \mathrm{~Hz}), 6.03$ (dd, $1 \mathrm{H}, 3-\mathrm{H}, J=14.9,3.4), 5.72$ (d, $1 \mathrm{H}, 6-\mathrm{H}, J=8.8$ ), 3.56 (dd, $\left.1 \mathrm{H}, 1^{\prime}-\mathrm{H}_{2}, J=-10.6,4.1\right), 3.40(\mathrm{~m}, 1 \mathrm{H}, 1-\mathrm{H}, J=$ $6.8,3.4), 3.34\left(\mathrm{dd}, 1 \mathrm{H}, 1^{\prime \prime}-\mathrm{H}_{2}, J=-10.6,2.7\right), 2.98$ $\left(1 \mathrm{H}, 5^{\prime}-\mathrm{H}_{\mathrm{eq}}\right), 2.91\left(\mathrm{~m}, 1 \mathrm{H}, 2^{\prime}-\mathrm{H}, J=4.1,2.7\right), 2.85(\mathrm{~m}$, $1 \mathrm{H}, 7-\mathrm{H}, J=8.8,6.7), 2.63\left(1 \mathrm{H}, 5^{\prime}-\mathrm{H}_{\mathrm{ax}}\right), 1.88-1.62(\mathrm{~m}$, $\left.4 \mathrm{H}, 3^{\prime}-, 4^{\prime}-\mathrm{H}_{2}\right), 1.26\left(\mathrm{~d}, 3 \mathrm{H}, 1-\mathrm{CH}_{3}, J=6.8\right), 1.06(\mathrm{~d}$, $\left.6 \mathrm{H}, 8-\mathrm{CH}_{3}, J=6.7\right) .{ }^{13} \mathrm{C}$ NMR: $\delta 140.72(\mathrm{C}-6), 133.45$ (C-3), 130.86 (C-4), 122.35 (C-5), 62.25 (C-1"), 60.20 $\left(\mathrm{C}-2^{\prime}\right), 56.01$ (C-2), 47.71 (C-5'), 31.13 (C-7), 28.52 (C-3'), 24.00 (C-4'), 21.76 (C-8), 20.86 (C-1). HRMS: 302.1098, calc. for $\mathrm{C}_{14} \mathrm{H}_{25} \mathrm{BrNO}(M+\mathrm{H}): 302.1119$. MS: $m / z(\%) 302 / 304\left[92,(M+H)^{+}\right], 270 / 272(45), 222(95)$, $123(100)$.

Synthesis of $\mathbf{8}$ and 9 via Swern oxidation and the Horner-Emmons reaction. ${ }^{6,7}$ Oxalyl chloride (104 ml, $1.21 \mathrm{mmol})$ was dissolved in dichloromethane $(8.0 \mathrm{ml})$ at $-60^{\circ} \mathrm{C}$ under argon. Dimethyl sulfoxide $(170 \mu$, $2.39 \mathrm{mmol})$ in dichloromethane $(2.0 \mathrm{ml})$ was added dropwise via a syringe from an adjacent cold bath. A $65: 35$ mixture of 6 and $7(1.00 \mathrm{mmol})$ in dichloromethane $(6.0 \mathrm{ml})$ was injected $10 \mathrm{~min}$ later, after which the reaction mixture was stirred for $35 \mathrm{~min}$ before triethylamine $(690 \mu \mathrm{l}, 4.94 \mathrm{mmol})$ was added. After $40 \mathrm{~min}$ at $-60{ }^{\circ} \mathrm{C}$ the reaction mixture was allowed to reach ambient temperature over $1 \mathrm{~h}$. The solvent was evaporated off and the residue was washed twice with heptane and 
once with ethyl acetate; these solutions were combined and then evaporated. Meanwhile, fresh phosphonate reagent was prepared: to a dispersion of sodium hydride $(24.00 \mathrm{mg}, 1.00 \mathrm{mmol})$ in tetrahydrofuran $(2 \mathrm{ml})$ at $0{ }^{\circ} \mathrm{C}$ under an argon atmosphere was added triethyl phosphonoacetate ( $224.19 \mathrm{mg}, 1.00 \mathrm{mmol}$ ) in tetrahydrofuran ( $1 \mathrm{ml})$. The triethyl phosphonoacetate was allowed to react for $1 \mathrm{~h}$ before the crude aldehyde, dissolved in anhydrous tetrahydrofuran $(2 \mathrm{ml})$, was injected into the mixture, which then was allowed to reach ambient temperature. After $1.5 \mathrm{~h}$ the reaction was complete as determined by TLC. The mixture was washed with $\mathrm{pH} 7$ buffer and water before it was dried over magnesium sulfate and finally evaporated in vacuo. Compounds 8 and 9 were obtained in a $65: 35$ ratio in $64 \%$ overall yield after separation on a Chromatotron ${ }^{\mathrm{TM}}$ with heptane-ethyl acetate-triethylamine $(90: 10: 5)$ as the eluent.

(E)-Ethyl 3-\{(2S)-1-[(2R and S)(3E,5Z)-5-bromo-7methyl-3,5-octadien-2-yl] tetrahydro-1H-pyrrol-2-yl $\}-2-$ propenoate (8 and 9 ). Yield: $237.01 \mathrm{mg}(64 \%)$. IR (film): v 2869s, $1707 \mathrm{~s}(\mathrm{C}=\mathrm{O}), 1648 \mathrm{~m}(\mathrm{C}=\mathrm{C}$ stretch, conjug. diene), 1460m, 1369s, 1264s, 1154s, 958s ( $\mathrm{CH}$ bend, trans-RCH=CHR). ${ }^{1} \mathrm{H}$ NMR: $\delta 6.84\left(\mathrm{dd}, 1 \mathrm{H}, 3^{\prime \prime}-\mathrm{H}, J=\right.$ $15.5,8.0), 6.03(\mathrm{~d}, 1 \mathrm{H}, 4-\mathrm{H}, J=14.8), 5.95(\mathrm{dd}, 1 \mathrm{H}$, $3-\mathrm{H}, J=14.8), 5.85\left(\mathrm{~d}, 1 \mathrm{H}, 2^{\prime \prime}-\mathrm{H}, J=15.5\right), 5.69$ (d, $1 \mathrm{H}$, 6-H, $J=8.5), 4.17$ (q, $\left.2 \mathrm{H}, \mathrm{OCH}_{2}, J=7.1\right), 3.36(1 \mathrm{H}$, 2-H), 3.30 (1 H, 5'- $\mathrm{H}_{2}$-eq), $2.96\left(1 \mathrm{H}, 2^{\prime}-\mathrm{H}, J=8.0\right), 2.84$ $(\mathrm{m}, 1 \mathrm{H}, 7-\mathrm{H}, J=8.5,6.7), 2.54\left(1 \mathrm{H}, 5^{\prime}-\mathrm{H}_{2}-\mathrm{ax}\right), 2.00-1.60$ $\left(4 \mathrm{H}, 3^{\prime}-\mathrm{H}_{2}, 4^{\prime}-\mathrm{H}_{2}\right), 1.28\left(\mathrm{t}, 3 \mathrm{H}, \mathrm{OCH}_{2} \mathrm{CH}_{3}, J=7.1\right)$, $1.22\left(\mathrm{~d}, 1 \mathrm{H}, 1-\mathrm{H}_{3}\right), 1.13\left(\mathrm{~d}, 2 \mathrm{H}, 1-\mathrm{H}_{3}\right), 1.02(\mathrm{~d}, 6 \mathrm{H}$, $\left.8-\mathrm{H}_{3}, \quad J=6.7\right) .{ }^{13} \mathrm{C}$ NMR: $\delta 166.65,151.77,151.50$, $140.60,140.30,137.31,133.41,130.84,129.27,122.54$, $121.33,120.83,61.93,61.75,60.30,60.20,57.78,56.03$, $49.72,47.05,31.86,31.53,31.13,31.09,29.69,23.11$, $22.98,21.76,20.84,17.29,14.27$. HRMS: 369.1304 , calc. for $\mathrm{C}_{18} \mathrm{H}_{28} \mathrm{BrNO}_{2}(M+\mathrm{H})$ : 369.1303. HRMS: 369.1313, calc. for $\mathrm{C}_{18} \mathrm{H}_{28} \mathrm{BrNO}_{2}(M+\mathrm{H})$ : 369.1303 .

Intramolecular Diels-Alder reaction. The diastereomeric mixture of 8 and $9(225.67 \mathrm{mg}, 0.6094 \mathrm{mmol})$ was dissolved in toluene $(75 \mathrm{ml})$ in a $100 \mathrm{ml}$ glass ampoule, which was repeatedly, i.e. three times, evacuated and flushed with argon before being sealed and placed in an oil bath at $100^{\circ} \mathrm{C}$. Samples for ${ }^{1} \mathrm{H}$ NMR samples were taken in order to monitor the progress of the IMDA. The minor triene was consumed quantitatively after $14 \mathrm{~h}$ at $100^{\circ} \mathrm{C}$; the temperature was raised to $120^{\circ} \mathrm{C}$ and the reaction continued for another $33 \mathrm{~h}$ before the major triene was consumed quantitatively too.

Separation of the IMDA isomers was achieved after HPLC chromatography using a mixture of ethyl acetatepentane-isopropyl alcohol-triethylamine $(60: 20: 15: 5)$ as the eluent. The four components were isolated in a total yield of $216.75 \mathrm{mg}(96 \%)$. The diastereomer 8 ( $146.69 \mathrm{mg}, 0.3961 \mathrm{mmol}$ ) gave $140.82 \mathrm{mg}(96 \%)$ of $\mathbf{1 0}$ and 11 in a ratio of $86: 14$ and the diastereomer 9 (78.98 $\mathrm{mg}, 0.2687 \mathrm{mmol}$ ) gave $75.82 \mathrm{mg}(96 \%)$ of 12 and 13 in a ratio of $90: 10$.
(5R,5aS,8R,9R,9aS,9bS)-Ethyl 7-Bromo-8-isopropyl-5methyl-2,3,5,5a,8,9,9a,9b-octahydro- $1 \mathrm{H}$-pyrrolo [2,1-a]isoindole-9-carboxylate $(10) .[\alpha]_{\mathrm{D}} 60.4\left(c 1.294, \mathrm{CHCl}_{3}\right)$. IR (film): v 1726s $(\mathrm{C}=\mathrm{O}) .{ }^{1} \mathrm{H}$ NMR: $\delta 6.06(1 \mathrm{H}, 6-\mathrm{H})$, 4.09 (q, $\left.2 \mathrm{H}, \mathrm{OCH}_{2}, J=7.2\right), 3.97(1 \mathrm{H}, 5-\mathrm{H}, J=7.2$ ), $3.93(\mathrm{~m}, 1 \mathrm{H}, 9 \mathrm{~b}-\mathrm{H}, J=11.4), 3.24\left(1 \mathrm{H}, 3-\mathrm{H}_{2}-\mathrm{eq}\right), 3.06$ $(\mathrm{m}, 1 \mathrm{H}, 5 \mathrm{a}-\mathrm{H}, J=11.4,7.2), 3.01(\mathrm{dd}, 1 \mathrm{H}, 9-\mathrm{H}, J=$ 11.4, 6.6), 2.95 (1 H, 8-H, $J=6.6), 2.89\left(1 \mathrm{H}, 3-\mathrm{H}_{2}-\mathrm{ax}\right)$, 2.38 (1 H, 1- $\mathrm{H}_{2}$-eq), $2.18(\mathrm{q}, 1 \mathrm{H}, 9 \mathrm{a}-\mathrm{H}, J=11.4), 2.08$ $\left(2 \mathrm{H}, 2-\mathrm{H}_{2}\right), 1.94\left(1 \mathrm{H}, 1-\mathrm{H}_{2}-\mathrm{ax}\right), 1.91(\mathrm{~m}, 1 \mathrm{H}, 10-\mathrm{H}$, $J=7.1), 1.24\left(\mathrm{t}, 3 \mathrm{H}, \mathrm{OCH}_{2} \mathrm{CH}_{3}, J=7.2\right), 1.12(\mathrm{~d}, 3 \mathrm{H}$, $\left.10-\mathrm{H}_{3}, J=7.1\right), 1.11\left(\mathrm{~d}, 3 \mathrm{H}, 5-\mathrm{H}_{3}, J=7.2\right), 1.02$ (d, $3 \mathrm{H}$, $\left.10-\mathrm{H}_{3}, J=7.1\right) .{ }^{13} \mathrm{C}$ NMR: $\delta 172.12(\mathrm{C}-\mathrm{H}), 127.05(\mathrm{C}-6)$, 126.60 (C-7), 70.97 (C-9b), $61.34\left(\mathrm{OCH}_{2}\right), 57.38$ (C-5), 52.32 (C-5a), 51.15 (C-8), 50.51 (C-9), 46.26 (C-3), 39.82 (C-9a), 32.31 (C-H), 30.27 (C-10), 28.87 (C-2), 24.13 $\left(10-\mathrm{CH}_{3}\right), 20.63\left(10-\mathrm{CH}_{3}\right), 14.50\left(\mathrm{OCH}_{2} \mathrm{CH}_{3}\right), 12.47$ (5$\mathrm{CH}_{3}$ ). HRMS: 369.1296, calc. for $\mathrm{C}_{18} \mathrm{H}_{28} \mathrm{BrNO}_{2}$ $(M+\mathrm{H}): 369.1303$.

( $5 \mathrm{R}, 5 a \mathrm{R}, 8 \mathrm{~S}, 9 \mathrm{~S}, 9 a \mathrm{R}, 9 b \mathrm{~S})$-Ethyl 7-Bromo-8-isopropyl-5methyl-2,3,5,5a,8,9,9a,9b-octahydro-1H-pyrrolo [2,1-a]isoindole-9-carboxylate (11). IR (film): $\vee 1726 \mathrm{~s}(\mathrm{C}=\mathrm{O})$. ${ }^{1} \mathrm{H}$ NMR: $\delta 6.14(\mathrm{~d}, 1 \mathrm{H}, 6-\mathrm{H}, J=2.0), 4.43(\mathrm{~m}, 1 \mathrm{H}$, $9 \mathrm{~b}-\mathrm{H}, J=8.0), 4.18$ (q, $\left.2 \mathrm{H}, \mathrm{OCH}_{2}, J=7.2\right), 3.45(1 \mathrm{H}$, $3-\mathrm{H}_{2}$-eq), 3.35 (m, $1 \mathrm{H}, 5-\mathrm{H}, J=12.0,7.2$ ), 3.02 (br d, $1 \mathrm{H}, 8-\mathrm{H}, J=5.6), 2.90(\mathrm{dd}, 1 \mathrm{H}, 9-\mathrm{H}, J=12.0,5.6), 2.67$ (1 H, 3- $\left.\mathrm{H}_{2}-\mathrm{ax}\right), 2.40(\mathrm{dt}, 1 \mathrm{H}, 9 \mathrm{a}-\mathrm{H}, J=12.0,8.0), 1.94$ $\left(2 \mathrm{H}, 2-\mathrm{H}_{2}\right), 2.02(\mathrm{~m}, 1 \mathrm{H}, 5 \mathrm{a}-\mathrm{H}, J=12.0,2.0), 1.92(1 \mathrm{H}$, $1-\mathrm{H}_{2}$-eq), $1.87(\mathrm{~m}, 1 \mathrm{H}, 10-\mathrm{H}, J=7.1), 1.30(\mathrm{t}, 3 \mathrm{H}$, $\left.\mathrm{OCH}_{2} \mathrm{CH}_{3}, J=7.2\right), 1.16\left(\mathrm{~d}, 3 \mathrm{H}, 10-\mathrm{H}_{3}, J=7.1\right), 1.38$ $\left(\mathrm{d}, 3 \mathrm{H}, 5-\mathrm{H}_{3}, J=7.2\right), 1.08$ (d, $\left.3 \mathrm{H}, 10-\mathrm{H}_{3}, J=7.1\right) .{ }^{13} \mathrm{C}$ NMR: $\delta 171.78(\mathrm{C}-11), 127.27(\mathrm{C}-6), 126.46(\mathrm{C}-7), 66.68$ (C-9b), $61.52\left(\mathrm{OCH}_{2}\right), 60.28(\mathrm{C}-5), 47.11(\mathrm{C}-5 \mathrm{a}), 51.68$ (C-8), 48.45 (C-9), 48.10 (C-3), 39.16 (C-9a), 26.73 (C-1), 30.47 (C-10), 25.80 (C-2), $24.62\left(10-\mathrm{CH}_{3}\right), 20.74$ $\left(10-\mathrm{CH}_{3}\right), 14.58\left(\mathrm{OCH}_{2} \mathrm{CH}_{3}\right), 12.91\left(5-\mathrm{CH}_{3}\right)$. HRMS: 369.1304 , calc. for $\mathrm{C}_{18} \mathrm{H}_{28} \mathrm{BrNO}_{2}(M+\mathrm{H}): 369.1303$.

( $5 \mathrm{~S}, 5 a \mathrm{~S}, 8 \mathrm{R}, 9 \mathrm{R}, 9 a \mathrm{~S}, 9 b \mathrm{~S})$-Ethyl 7-Bromo-8-isopropyl-5methyl-2,3,5,5a,8,9,9a,9b-octahydro-1H-pyrrolo [2,1-a]isoindole-9-carboxylate (12). $[\alpha]_{\mathrm{D}} 35.5\left(c 0.664, \mathrm{CHCl}_{3}\right)$. IR (film): v 1726s $(\mathrm{C}=\mathrm{O}) .{ }^{1} \mathrm{H}$ NMR: $\delta 6.17(1 \mathrm{H}, 6-\mathrm{H})$, $4.13\left(\mathrm{q}, 2 \mathrm{H}, \mathrm{OCH}_{2}, J=7.2\right), 3.48(1 \mathrm{H}, 9 \mathrm{~b}-\mathrm{H}), 3.10$ (1 H, 3- $\mathrm{H}_{2}$-eq), $2.96(1 \mathrm{H}, 9-\mathrm{H}, J=11.3), 2.93(1 \mathrm{H}$, 8-H), 2.57 (1 H, 3- $\left.\mathrm{H}_{2}-\mathrm{ax}\right), 2.45$ (dd, $1 \mathrm{H}, 5-\mathrm{H}, J=11.3$, 6.0), 2.27 (t, $1 \mathrm{H}, 5 \mathrm{a}-\mathrm{H}, J=11.3), 2.11\left(1 \mathrm{H}, 1-\mathrm{H}_{2}-\mathrm{eq}\right)$, $1.97(\mathrm{~m}, 1 \mathrm{H}, 10-\mathrm{H}, J=7.1), 1.93\left(1 \mathrm{H}, 1-\mathrm{H}_{2}-\mathrm{ax}\right), 1.92$ $\left(2 \mathrm{H}, 2-\mathrm{H}_{2}\right), 1.86(\mathrm{t}, 1 \mathrm{H}, 9 \mathrm{a}-\mathrm{H}, J=11.3), 1.28(\mathrm{t}, 3 \mathrm{H}$, $\mathrm{OCH}_{2} \mathrm{CH}_{3}, J=7.2$ ), 1.24 (d, $\left.3 \mathrm{H}, 5-\mathrm{H}_{3}, J=6.0\right), 1.13$ (d, $\left.3 \mathrm{H}, 10-\mathrm{H}_{3}, J=7.1\right), 1.05$ (d, $\left.3 \mathrm{H}, 10-\mathrm{H}_{3}, J=7.1\right) .{ }^{13} \mathrm{C}$ NMR: $\delta 172.64$ (C-11), 129.10 (C-6), 125.65 (C-7), 67.93 (C-9b), 64.29 (C-5), $60.91\left(\mathrm{OCH}_{2}\right), 55.52$ (C-5a), 52.90 (C-3), 51.65 (C-8), 51.01 (C-9), 44.70 (C-9a), 33.11 (C-1), 30.33 (C-10), 27.76 (C-2), $24.08\left(10-\mathrm{CH}_{3}\right), 20.80$ $\left(10-\mathrm{CH}_{3}\right), 17.97\left(5-\mathrm{CH}_{3}\right), 14.52\left(\mathrm{OCH}_{2} \mathrm{CH}_{3}\right)$. HRMS: 369.1298 , calc. for $\mathrm{C}_{18} \mathrm{H}_{28} \mathrm{BrNO}_{2}: 369.1303$. 
(5S,5aR,8S,9R,9aS,9bS)-Ethyl 7-Bromo-8-isopropyl-5methyl-2,3,5,5a,8,9,9a,9b-octahydro-1H-pyrrolo [2,1-a]isoindole-9-carboxylate (13). IR (film): v 1726s $(\mathrm{C}=\mathrm{O})$. ${ }^{1} \mathrm{H}$ NMR: $\delta 6.13(\mathrm{dd}, 1 \mathrm{H}, 6-\mathrm{H}, J=5.9), 4.20(\mathrm{q}, 2 \mathrm{H}$, $\left.\mathrm{OCH}_{2}, J=7.2\right), 3.99$ ( $\left.1 \mathrm{H}, 9 \mathrm{~b}-\mathrm{H}\right), 3.34$ ( $1 \mathrm{H}, 3-\mathrm{H}_{2}$-eq), $3.31(\mathrm{dd}, 1 \mathrm{H}, 5-\mathrm{H}, J=6.6,5.9), 2.86(\mathrm{~m}, 1 \mathrm{H}, 8-\mathrm{H}, J=$ 9.5), $2.73\left(1 \mathrm{H}, 3-\mathrm{H}_{2}-\mathrm{ax}\right), 2.66(\mathrm{t}, 1 \mathrm{H}, \mathrm{H} 9, J=12.1)$, $2.56(\mathrm{~m}, 1 \mathrm{H}, 10-\mathrm{H}, J=7.1), 2.44(\mathrm{~m}, 1 \mathrm{H}, 5 \mathrm{a}-\mathrm{H}, J=7.3$, 5.9), 2.25 ( $1 \mathrm{H}, 1-\mathrm{H}_{2}$-eq), $2.18(\mathrm{~m}, 1 \mathrm{H}, 9 \mathrm{a}-\mathrm{H}, J=12.1$, 7.3), $1.96\left(2 \mathrm{H}, 2-\mathrm{H}_{2}\right), 1.49\left(1 \mathrm{H}, 1-\mathrm{H}_{2}-\mathrm{ax}\right), 1.36(\mathrm{~d}, 3 \mathrm{H}$, $\left.5-\mathrm{H}_{3}, J=6.6\right), 1.30\left(\mathrm{t}, 3 \mathrm{H}, \mathrm{OCH}_{2} \mathrm{CH}_{3}, J=7.2\right), 0.93$ (d, $\left.3 \mathrm{H}, 10-\mathrm{H}_{3}, J=7.1\right), 0.84\left(\mathrm{~d}, 3 \mathrm{H}, 10-\mathrm{H}_{3}, J=7.1\right) .{ }^{13} \mathrm{C}$ NMR: $\delta 175.29$ (C-11), 131.93 (C-7), 125.82 (C-6), 67.88 $(\mathrm{C}-9 \mathrm{~b}), 61.80\left(\mathrm{OCH}_{2}\right), 61.30(\mathrm{C}-5), 48.43(\mathrm{C}-8), 47.50$ (C-3), 46.28 (C-9a), 44.44 (C-5a), 43.67 (C-9), 33.24 (C-1), 30.68 (C-10), $26.06(\mathrm{C}-2), 20.06\left(10-\mathrm{CH}_{3}\right), 16.23$ $\left(10-\mathrm{CH}_{3}\right), 14.60\left(\mathrm{OCH}_{2} \mathrm{CH}_{3}\right), 13.72\left(5-\mathrm{CH}_{3}\right)$. HRMS: 369.1301 , calc. for $\mathrm{C}_{18} \mathrm{H}_{28} \mathrm{BrNO}_{2}(M+\mathrm{H}): 369.1303$.

Acknowledgements. We thank Mr. Einar Nilsson for the mass analyses and the Swedish Natural Science Research Council for financial support of this work.

\section{References}

1. Tsirk, A., Gronowitz, S. and Hörnfeldt, A.-B. To be published.

2. Karlsson, J. O., Gronowitz, S. and Hallberg, A. Chem. Scr. 20 (1982) 37.

3. van Tilborg, W. J. M. Synth. Commun. (1976) 583.

4. Tsirk, A., Gronowitz, S. and Hörnfeldt, A.-B. Tetrahedron $51(1995) 7035$.
5. Professor Jan Sandström. Personal communication.

6. Ireland, R. E. and Norbeck, D. W. J. Org. Chem. 50 (1985) 2198

7. Kametani, T., Higashiyama, K. Otomatsu, H. and Honda, T. Isr. J. Chem. 27 (1986) 57.

8. Whitesell, J. K., LaCour, T., Lovell, R. L., Pojman, J., Ryan, P. and Yamada-Nosaka, A. J. Am. Chem. Soc. 110 (1988) 991.

9. Tsirk, A., Gronowitz, S. and Hörnfeldt, A.-B. Helv. Chim. Acta (1997). In press.

10. McGregor, S. D. and Lemal, D. M. J. Am. Chem. Soc. 88 (1966) 2858.

11. Mock, W. L. J. Am. Chem. Soc. 97 (1975) 3673.

12. Gronowitz, S., Hallberg, A. and Nikitidis, G. Tetrahedron 43 (1987) 4793.

13. Gronowitz, S., Hörnfeldt, A.-B., Lukevics, E. and Pudova, O. Synthesis (1994) 40

14. Tsirk, A., Gronowitz, S. and Hörnfeldt, A.-B. Tetrahedron 53 (1997) 771.

15. McDowell, S. T. and Stirling, C. J. M. J. Chem. Soc. B (1967) 343.

16. McDowell, S. T. and Stirling, C. J. M. J. Chem. Soc. (1967) 349.

17. McDowell, S. T. and Stirling, C. J. M. J. Chem. Soc. (1967) 351 .

18. Houk, K. N., Paddon-Row, M. N., Rondan, N. G., Wu, Y.-D., Brown, F. K., Spellmayer, D. C., Metz, J. T., Li, Y. and Loncharich, R. J. Science 231 (1986) 1108.

19. Rudolf, K.. Hawkins, J. M.. Loncharich. R. J. and Houk. K. N. J. Org. Chem. 53 (1988) 3879.

20. Osman, R., Namboodiri, K., Weinstein, H. and Rabinowitz, J. R. J. Am. Chem. Soc. 110 (1988) 1701.

21. SPARTAN version 4.0, Wavefunction Inc., Von Karman, Suite 370, Irvine, California 92715, USA.

22. Morokuma, K. Acc. Chem. Res. (1977) 294.

Received April 21, 1997. 